\title{
Surface Induced Ni(II) Precipitation at the Palygorskite-Solution Interface Revealed by EXAFS, HRTEM, and DRS
}

\author{
XINXIN MO ${ }^{1}$, MATTHEW G. SIEBECKER ${ }^{2}$, WENXIAN \\ $\mathrm{GOU}^{1}, \mathrm{WEI} \mathrm{LI}^{1}$ * \\ ${ }^{1}$ School of Earth Sciences and Engineering, Nanjing \\ University, Nanjing 210023, China (*correspondence: \\ liwei_isg@nju.edu.cn) \\ ${ }^{2}$ Department of Plant and Soil Science, Texas Tech \\ University, Lubbock, Texas 79409, United States
}

Sorption reactions at the mineral/water interface control the fate and transport of trace metals on larger scale in aqueous geochemical environments. However, a good understanding of the structure-reactivty relationship at mineral/water interface is still not clearly established. While extensive studies have focues on layered structure clay minearls, we chose a chain-type clay mineral (palygorskite) as the adsorbent and investigated the mechanisms of $\mathrm{Ni}$ uptake with a combination of macroscopic batch studies, transmission electron microscopy (TEM), diffuse reflectance spectroscopy (DRS), and extended X-ray absorption fine structure (EXAFS) spectroscopy.

The results demonstrated that below $\mathrm{pH} 6$, the sorption was dominated by outer-sphere and inner-sphere surface complexation. Above $\mathrm{pH} 7.5$, the EXAFS data suggested the formation of $\alpha-\mathrm{Ni}(\mathrm{OH})_{2}$ type of precipitate, in agreement with its linear type sorption isotherm. A special finding is that the precipitates can form at a very low Ni concentration ( $~$ $0.07 \mathrm{mM}$ ), with the sorption density of $\Gamma=0.09 \mu \mathrm{mol} \mathrm{m}{ }^{-2}$, which corresponds to a $0.3 \%$ monolayer coverage for palygorskite. In contrast, at this low level of $\mathrm{Ni}$ concentration, surface precipitates have not form with $\gamma-\mathrm{Al}_{2} \mathrm{O}_{3}$. We assume that $\mathrm{Ni}$ can be directly induced to precipitate on palygorskite surface (we call it "continuous nucleation"), differing from the traditional adsorption-to-polymerization process on $\gamma$ $\mathrm{Al}_{2} \mathrm{O}_{3}$ surface (we call it "staged nucleation").

We further tested the role of mineral surface in the $\mathrm{Ni}$ precipitates formation. It was revealed that linear shape isotherm was also observed for $\mathrm{Ni}$ sorption on sepiolite, a clay with similar structure and chemical composition of palygorskite, indicating a similar reactivity of the both chainstructrue phyllosilicates. The findings not only improved the current understanding of metal sequestration at the mineral/water interfaces, but also provided new insights into the surface reactivity of clay minerals. 